\title{
17
}

\section{Addressing Chronic Flooding in a Dynamic River System through an Ice Management Plan}

\author{
David C. Arseneau, Michael A. Gregory, Ray H. Tufgar, Alec Scott \\ and Ross Wilson
}

The Lower Ausable River discharges into Lake Huron near the hamlet of Port Franks, south of Grand Bend, Ontario. Port Franks has a long history of icerelated flooding problems. The Ausable Bayfield Conservation Authority (ABCA) has conducted several hydraulic studies of the Lower Ausable River in the past to identify critical ice jam formation areas and recommend measures to minimize flooding hazards to properties along the river.

The ABCA has recently undertaken an update of these studies, covering a $9.2 \mathrm{~km}(5.7 \mathrm{mi})$ reach that was originally channelized for drainage purposes over 130 years ago. The objective of the study was to identify river sections most susceptible to the formation of ice jams through hydraulic modeling, and to recommend a set of mitigative measures that address the resultant flooding. Key project challenges have included the economy of data collection methodologies (e.g., the use of digital bathymetric soundings and land terrain models, augmented with new GPS survey) as well as addressing new environmental permitting requirements.

This chapter presents a summary of the ice management study procedures and findings, including a summary of the theory of ice jam formation, hydraulic modeling methodologies, the identification and prioritization of susceptible ice jam locations, and an overview of mitigative measures (that is, structural and operational controls) to minimize ice jam potential. A key highlight of this

Arseneau, D., M. Gregory, R. Tufgar, A. Scott and R. Wilson. 2010. "Addressing Chronic Flooding in a Dynamic River System through an Ice Management Plan." Journal of Water Management Modeling R236-17. doi: 10.14796/JWMM.R236-17.

(C) CHI 2010 www.chijournal.org ISSN: 2292-6062 (Formerly in Dynamic Modeling of Urban Water Systems. ISBN: 978-0-9808853-3-0) 
chapter is a practical guide to addressing new environmental permitting challenges that are affecting many water resources projects throughout Canada: namely, new government protocols related to sampling procedures and potential relocation plans with respect to native bivalve populations (mussels).

\subsection{Background}

\subsubsection{Study Area}

The Ausable River drains approximately $1250 \mathrm{~km}^{2}\left(480 \mathrm{mi}^{2}\right)$ of primarily rural areas consisting largely of agricultural land uses. In 1876 , as the need for prime agricultural land increased, the lakes of a remnant coastal lagoon between Grand Bend and Port Franks were drained, and the Lower Ausable River Cut was made by blocking the river at the Old Iron Bridge (indicated by Ausable River arrow) as shown in Figure 17.1. This cut rerouted the portion of the river from its historic flow path towards Grand Bend and directed the river towards Port Franks (Ontario Department of Planning and Development, 1949). In 1949, the river was straightened from the old Ausable Channel to Lake Huron.

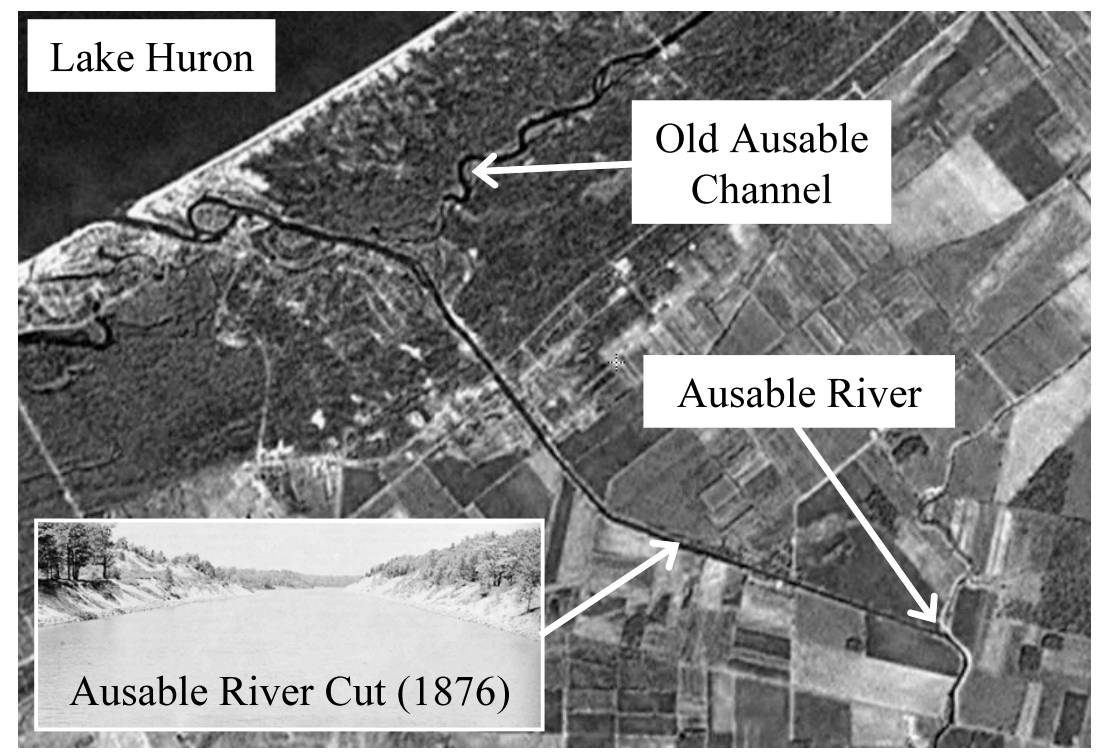

Figure 17.1 Project study area. 
The Lower Ausable River is generally straight as a result of the construction projects in 1876 and 1949. The river is largely uniform, with an average channel width of $72 \mathrm{~m}(235 \mathrm{ft})$ and an average bankfull depth of $2.5 \mathrm{~m}(8 \mathrm{ft})$, although these dimensions can vary. These variations are a result of the significant sediment loads moving in the river and deposition process. The river is very slow moving as a result of the width and Lake Huron controlling river levels.

\subsubsection{Problem Statement}

The Port Franks area has been subject to significant erosion and ice-related flooding in recent years. Several geometric and geological factors regarding the Ausable River and the mouth at Lake Huron have contributed to these problems and also make it difficult to control or minimize the hazards. Some of these factors are the following:

- The Ausable River is subject to a significant amount of sediment deposition as a result of the size of the river, flow characteristics, flat bedslope and backwater from Lake Huron. This reduces the depth of the river and its ability to carry spring flows during ice movement (and blockage), leading to flooding conditions. Low overbanks and low lying adjacent lands result in significant flood potential when the river overtops its banks;

- Shifting sediment results in significant changes in river bed geometry, influencing the potential for ice jam formation;

- Sharp bends near the mouth of the river affect ice movement, and under certain conditions, contribute to the potential for blockages;

- The side channel of the first bend (near the original cut) provides for some ice storage; and

- Lake conditions affect the ability of ice to move and potential for flooding.

As are most streams and rivers, the Ausable River is in a constant state of transition. Although flooding, erosion and sedimentation are common stream processes, the problems are exacerbated by the effects of ice jams in the river and by fluctuating levels in Lake Huron. During high lake level conditions, ice jam and flooding problems predominate, whereas low lake levels lead to increased bank erosion and river migration problems. Lake levels have been low since the late 1990s, which shifted the concern to focus on erosion control 
works; however, the threat of flooding due to ice jams remains, and studies on developing effective ice management plans continue.

Past studies have shown that the river has significant sediment deposition. Scour has also occurred, primarily during ice jams, resulting in a highly variable bed profile that changes significantly on an annual basis. There has been a tendency for the river to move to a more natural meandering shape, as evidenced by past erosion problems. Erosion control works have held the river to its current location. Old oxbows from the original river area provide some flow relief during ice jams, but this relief is somewhat limited.

Ice jamming has been an ongoing problem in Port Franks. Ice cover reduces the cross-sectional area through which flow is conveyed, which can accelerate velocities, thereby increasing erosive forces. The ice cover formation may also not be consistent and could divert flows in alternate directions. The geometric conditions in this area are ideal for ice formation coupled with a dynamic sandbased streambed and minimal bed slope.

As a result, $\mathrm{ABCA}$ initiated an ice management study to:

- Identify, evaluate and compare a set of appropriate options available for ice management; and

- Recommend the most cost-effective approach and implementation strategy that is acceptable to environmental permitting agencies.

\subsection{Ice Jam Formation}

Ice formation is a natural occurrence in cold climates and is determined by hydrologic and meteorological conditions. In large rivers with a low flow velocity, such as the Ausable River, ice will initially form from thermal growth as in lakes. As winter progresses, the surface water loses heat to the cool air, particularly on nights with a slight wind, a clear sky and low temperature.

Eventually, the surface water reaches the freezing point, and ice forms as small, thin disc-shaped plates which join together. At this point the ice has considerable cohesive properties. The next step is the formation of another layer of small thin plates, which cover the initial plates. This process will cease or be reduced depending on meteorological conditions. The early part of this process creates a great deal of water vapour, which may extend up to $30 \mathrm{~m}(100 \mathrm{ft})$ above the ice.

The initial cohesive ice is known as frazil ice, which will bind to most surfaces. An example of this phenomenon is the ability of frazil ice to cling to the 
iron grating at the entrance of a hydraulic power plant, causing temporary shutdowns.

Ice cover on rivers can take on many different forms (such as pure ice cover, frazil ice accumulation or ice floes,), all of which can contribute to an ice jam, especially ice floes. Ice floes consist of broken pieces of an ice cover, and generally have a significant mass, providing both strength and size that, when a jam forms, results in significant constriction of flows and a resulting increase in water levels that can cause flooding. Ice floes have been responsible for the flooding issues at Port Franks.

\subsubsection{Upstream River Conditions}

Conditions within the upstream reaches of the Ausable River (in the natural portion of the river, upstream of the Old Iron Bridge) contribute a considerable quantity of ice to the study area. It is estimated that a surface area of approximately $2 \mathrm{~km}^{2}\left(0.8 \mathrm{mi}^{2}\right)$ in the upstream river can produce and supply ice to the Lower Ausable River reach (the Cut, from the Old Iron Bridge to Lake Huron). Considering that the surface area of the Lower Ausable River is approximately $0.5 \mathrm{~km}^{2}\left(0.2 \mathrm{mi}^{2}\right)$, the supply of ice from the upstream river can increase the potential for ice jams significantly.

This ice jam potential is influenced by the following conditions:

- Bank widths in the upper reaches generally range from $30 \mathrm{~m}$ to $65 \mathrm{~m}(100 \mathrm{ft}$ to $200 \mathrm{ft})$ with only a short section exceeding $100 \mathrm{~m}$ (300 ft). At typical spring flows which produce ice jams $\left(200 \mathrm{~m}^{3} / \mathrm{s}\right.$ or $\left.7060 \mathrm{ft}^{3} / \mathrm{s}\right)$, flow depths range from $5 \mathrm{~m}$ to $10 \mathrm{~m}$ (16 ft to $33 \mathrm{ft}$ );

- The river bottom in the upper reaches is moderately undulating, but not to the extent of the lower study reaches. Froude numbers seldom exceed 0.275 and velocities are generally in the range $0.9 \mathrm{~m} / \mathrm{s}$ to $1.2 \mathrm{~m} / \mathrm{s}(3 \mathrm{ft} / \mathrm{s}$ to $4 \mathrm{ft} / \mathrm{s})$, indicating a lower chance of ice jams in the upper reaches;

- Ice crystals which eventually form frazil ice have ample opportunity to develop throughout the slow moving reaches along the river; and

- Given the wide geometric properties of the upstream reaches, large quantities of ice floes can be expected to be produced and accumulated downstream. 


\subsubsection{Hydraulic Indicators}

If the flow velocity increases with a corresponding increase in streamflow (such as during a melt event) ice floes will be carried downstream, possibly to the extent of filling the waterway and thus creating an ice jam. The previous ice management studies (Triton, 1991; TSH and Lazier, 1999; TSH, 2000) sought physical indicators for the prediction of ice jams due to ice floes and it was found through literature review (Michel, 1978; Pariset, 1966) that the Froude number could be used for this purpose.

The Froude number is a dimensionless value that characterizes inertial and gravitational forces. For cross-sections with a uniform depth of flow, the Froude number can be simplified according to Equation 17.1:

$$
F r=\frac{V}{\sqrt{g d}}
$$

where:

$$
\begin{aligned}
F r & =\text { Froude number } \\
V & =\text { average flow velocity }(\mathrm{m} / \mathrm{s}), \\
g & =\text { acceleration due to gravity }\left(9.81 \mathrm{~m} / \mathrm{s}^{2}\right), \text { and } \\
d & =\text { depth of flow }(\mathrm{m})
\end{aligned}
$$

A previous engineering study produced a table of Froude numbers for the Lower Ausable River (Triton, 1991). These procedures were updated and applied in two subsequent studies in 1999 and 2000 by Totten Sims Hubicki (TSH and Lazier, 1999; TSH, 2000) to determine ice jam potential using channel geometry and hydraulic characteristics. These procedures were used in the current study.

The suitability of the Froude number to predict ice cover break up and subsequent ice jam formation arises from analysis of the Pariset's $x$ factor (Pariset, 1966), which is a dimensionless value using ice mass density and friction as a function of cover thickness to depth ratio for the determination of ice cover stability. It is noted that as water velocity and quantity increase, the $x$ factor increases. If the $x$ factor increases without increasing the ice cover thickness ratio as in the case of abrupt changes in flow velocity, the result would be outside the stability curve and ice cover would become unstable.

As a result of the analysis of the Parisets $x$ factor, the conditions that influence ice jam potential can be summarized as follows:

- Surface flow velocity $>1.0 \mathrm{~m} / \mathrm{s}$;

- Froude number $>0.275$ (this condition occurs at break-up veloc- 
ity and generally indicates a high potential for ice jams); and

- Critical flow conditions (defined as approximately $60 \%$ of the 100 y return period streamflow, which is described in Section 17.3.2 below).

Based on these conditions, ice jam susceptibility of the individual river sections was identified in this study according to various risk categories. The risk categories are defined by the following Froude number ranges under critical flow conditions:

- High risk: Froude number $>0.25$. River sections identified in the high risk category are addressed in the evaluation of alternatives in Section 17.4 below;

- Medium risk: Froude number $>0.20$ and $<0.25$. Improvement alternatives were not evaluated for river sections identified in the medium risk category, however these locations are recommended for continued surveillance as part of the management plan; and

- Low risk: Froude number $<0.20$. No ice management activities are recommended for these river sections.

\subsection{Existing System Characterization}

An assessment of existing conditions was carried out to evaluate current conditions and processes which will affect the options available and the evaluation of alternatives. This section describes the flow analysis and existing system hydraulic analysis that was used as the basis for development of ice management options and their evaluation. The existing conditions analysis includes a characterization of the hydrology, hydraulics, stream morphology and natural environment within the study area.

\subsubsection{Lake Levels}

Water levels within a large river system vary considerably on a short term basis in response to natural conditions such as rainfall and snowmelt in the feeding watersheds. Water levels in the Lower Ausable River are particularly sensitive to water levels in Lake Huron as well as wind set-up. Effects are significant near the outlet of the river and diminish as distance increases upstream. Figure 17.2 plots the average annual levels in Lake Huron recorded by Environment Canada from 1918 to 2001. By smoothing the peaks and the lows, a cyclical pattern can emerge from the potted values as seen in the trendline. 


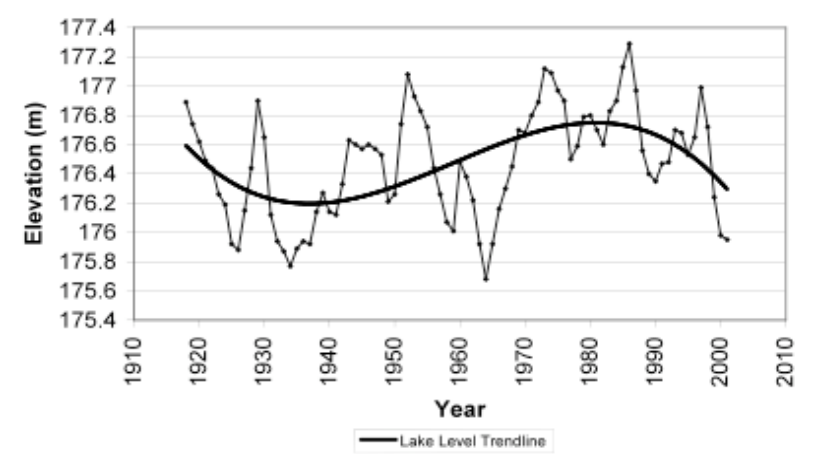

Figure 17.2 Average annual Lake Huron levels.

The maximum and minimum annual average levels in Lake Huron for the period of record 1918-2001 are $177.29 \mathrm{~m}$ and $175.68 \mathrm{~m}$ respectively. The average value dropped below $176 \mathrm{~m}$ in 2000 with a further decline in 2001. All elevations in this report are referenced to the International Great Lakes Datum (IGLD), 1985. The design water level used for the Armstrong West Erosion Control project (TSH, 2005) was 176.0, selected as a representative low water condition. The Armstrong West project is located within the study area at the mouth of the Lower Ausable River and described in detail elsewhere (Gregory et al., 2008).

\subsubsection{Streamflow Analysis}

An analysis of 58 years' worth of daily maximum streamflow data from the monitoring gauge near Springbank, Ontario was conducted as part of this study. Although the gauge is located upstream of the study area, the incremental drainage area between the gauge and the study area is not significant. Figure 17.3 shows the daily maximum streamflows for the complete period of record, 1945-2003. The figure also highlights the highest daily maximum flow in each year, which was used to define the partial duration time series in the plotting position analysis described below.

Figure 17.4 shows the results of the time series analysis of streamflows. Two methods were used to determine the streamflow statistics:

1. Complete duration plotting position analysis of daily maximum flows; and

2. Partial duration plotting position analysis of annual maximum daily flows. 


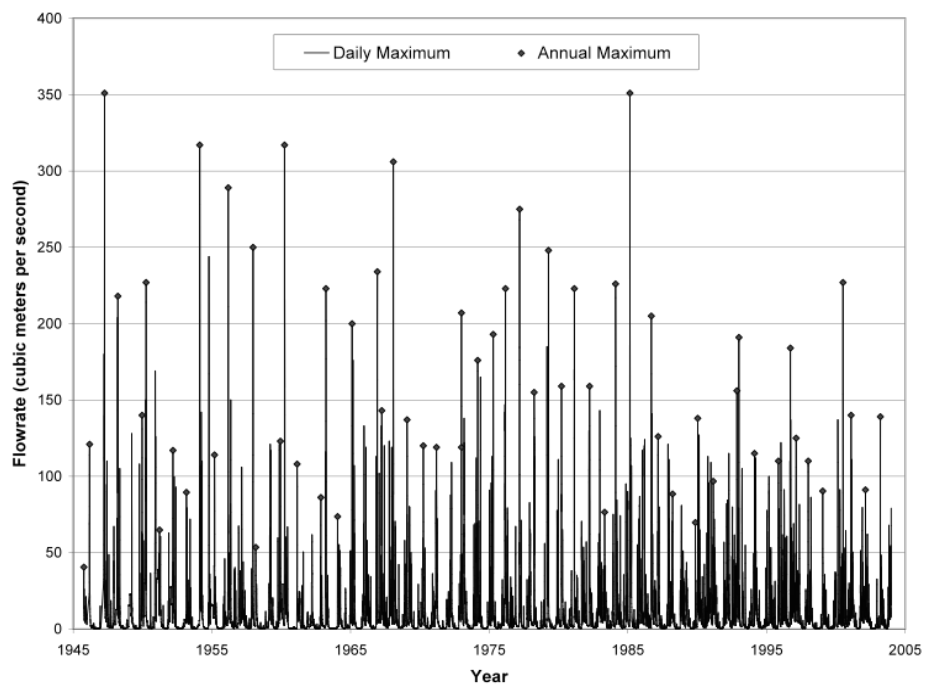

Figure 17.3 Daily and annual maximum streamflows, Ausable River near Springbank, Ontario.

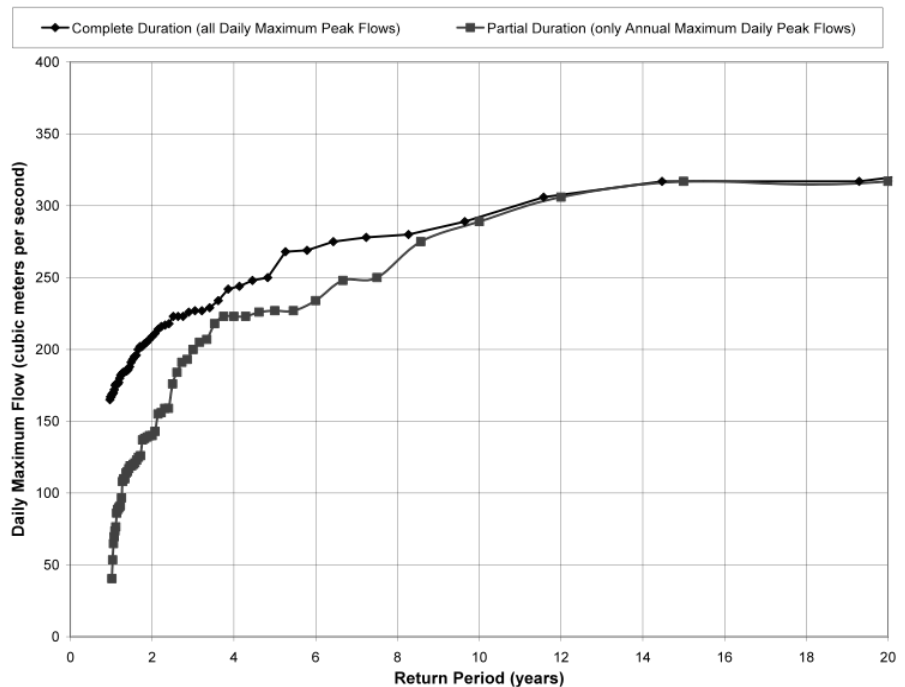

Figure 17.4 Plotting position analysis—streamflow data for Ausable River (1945-2003). 
The analysis sorts and ranks the streamflow values in decreasing order and assigns a probability of annual occurrence by using the plotting position expression: $(N+1) / m$, where $N$ is the total number of years of record; and $m$ is the rank of a given monthly value. This expression determines the return period of each streamflow value.

It is common in streamflow analysis that the return periods determined from the complete and partial durations are different for the more frequent events, but yield similar results for the more rare events, as is indicated in Figure 17.4. The figure also illustrates the common hydrologic phenomena that the mean annual streamflow (1 y return period flow with an average annual recurrence interval of one year) based on daily maximum values is statistically similar to the 2.33 y return event based on annual maxima. The time series analysis results indicated the statistics shown in Table 17.1.

Table 17.1 Streamflow statistics.

\begin{tabular}{cc}
\hline Return Period & Streamflow \\
\hline $1 \mathrm{y}$ & $170 \mathrm{~m}^{3} / \mathrm{s}\left(6000 \mathrm{ft}^{3} / \mathrm{s}\right)$ \\
$2 \mathrm{y}$ & $210 \mathrm{~m}^{3} / \mathrm{s}\left(7420 \mathrm{ft}^{3} / \mathrm{s}\right)$ \\
$5 \mathrm{y}$ & $250 \mathrm{~m}^{3} / \mathrm{s}\left(8830 \mathrm{ft}^{3} / \mathrm{s}\right)$ \\
$10 \mathrm{y}$ & $290 \mathrm{~m}^{3} / \mathrm{s}\left(10240 \mathrm{ft}^{3} / \mathrm{s}\right)$ \\
$25 \mathrm{y}$ & $320 \mathrm{~m}^{3} / \mathrm{s}\left(11300 \mathrm{ft}^{3} / \mathrm{s}\right)$ \\
$100 \mathrm{y}$ & $350 \mathrm{~m}^{3} / \mathrm{s}\left(12360 \mathrm{ft}^{3} / \mathrm{s}\right)$ \\
\hline
\end{tabular}

As noted previously, critical flow conditions for ice jam susceptibility are defined as approximately $60 \%$ of the $100 \mathrm{y}$ return period streamflow. Based on the streamflow analysis described above, the critical flow value is therefore $200 \mathrm{~m}^{3} / \mathrm{s}\left(7060 \mathrm{ft}^{3} / \mathrm{s}\right)$.

\subsubsection{Hydraulic Analysis}

The analysis of hydraulic conditions in the Ausable River Cut involved the collection of extensive survey data using two main sources: bathymetric soundings and GPS surveying. The bathymetric soundings were developed into a digital terrain model using GIS software, and were combined with the GPS survey of the river bank and floodplain areas to form the cross-sections for use in the hydraulic model. The Hydraulic Engineering Center River Analysis System (HEC-RAS) model was used to simulate the hydraulic characteristics of the study area.

As established in the previous sections, the critical flow condition for determination of ice cover stability used in this study is $200 \mathrm{~m}^{3} / \mathrm{s}\left(7060 \mathrm{ft}^{3} / \mathrm{s}\right)$, and 
this value was used as the design flow in the hydraulic simulations. For a model boundary condition, the lake level at the river mouth was set at an elevation of $176.0 \mathrm{~m}$, the design water level identified in Section 17.3.1 above. Although this corresponds to a low water datum based on historical lake levels, it is representative of lake levels for the period 2006-2008.

A continuous ice cover of $0.30 \mathrm{~m}$ (12 in.) was assumed for the entire reach, as established in previous hydraulic analyses of this area. A Manning's $n$ value of 0.008 was applied as the roughness factor for the ice surface, according to published literature values (Haestad Methods, 2003).

The results of the hydraulic model produced several areas along the reach that were susceptible to ice jams, according to the criteria defined previously (high risk for Froude number $>0.25$ and medium risk for Froude number $>0.20$ and $<0.25$ ).

Table 17.2 summarizes the high risk and medium risk river cross-sections. River section 1 at the mouth of the Ausable River appears as a high-risk area because the hydraulic model does not represent the dampening effect in Lake Huron. If the lake storage were accounted for in the model, the Froude number would decrease and not be considered high risk. Further, this portion of the river is already under an annual maintenance plan and undergoes yearly dredging. Thus, it was not incorporated into the proposed management plan. Figures 17.5 and 17.6 show the location of the priority ice jam potential river sections.

Table 17.2 Summary of potential ice jam locations.

\begin{tabular}{|r|r|r|}
\hline $\begin{array}{c}\text { River } \\
\text { Station }\end{array}$ & Froude No. & $\begin{array}{c}\text { Velocity } \\
\text { (m/s) }\end{array}$ \\
\hline \multicolumn{2}{|c|}{ High Risk Sections } \\
\hline 1 & 0.390 & 1.42 \\
\hline 5.1 & 0.283 & 1.18 \\
\hline 9 & 0.277 & 1.26 \\
\hline 10 & 0.396 & 1.74 \\
\hline 11 & 0.299 & 1.12 \\
\hline 16 & 0.256 & 1.28 \\
\hline 27200 & 0.271 & 1.70 \\
\hline Medium Risk Sections \\
\hline 4 & 0.248 & 1.18 \\
\hline 5 & 0.236 & 0.80 \\
\hline 7.1 & 0.204 & 1.04 \\
\hline 7.2 & 0.205 & 0.89 \\
\hline 8 & 0.207 & 1.03 \\
\hline 12 & 0.205 & 0.97 \\
\hline 13 & 0.226 & 1.16 \\
\hline 15050 & 0.200 & 1.09 \\
\hline 21600 & 0.219 & 1.35 \\
\hline 21601 & 0.216 & 1.34 \\
\hline 24100 & 0.205 & 1.29 \\
\hline & & \\
\hline
\end{tabular}




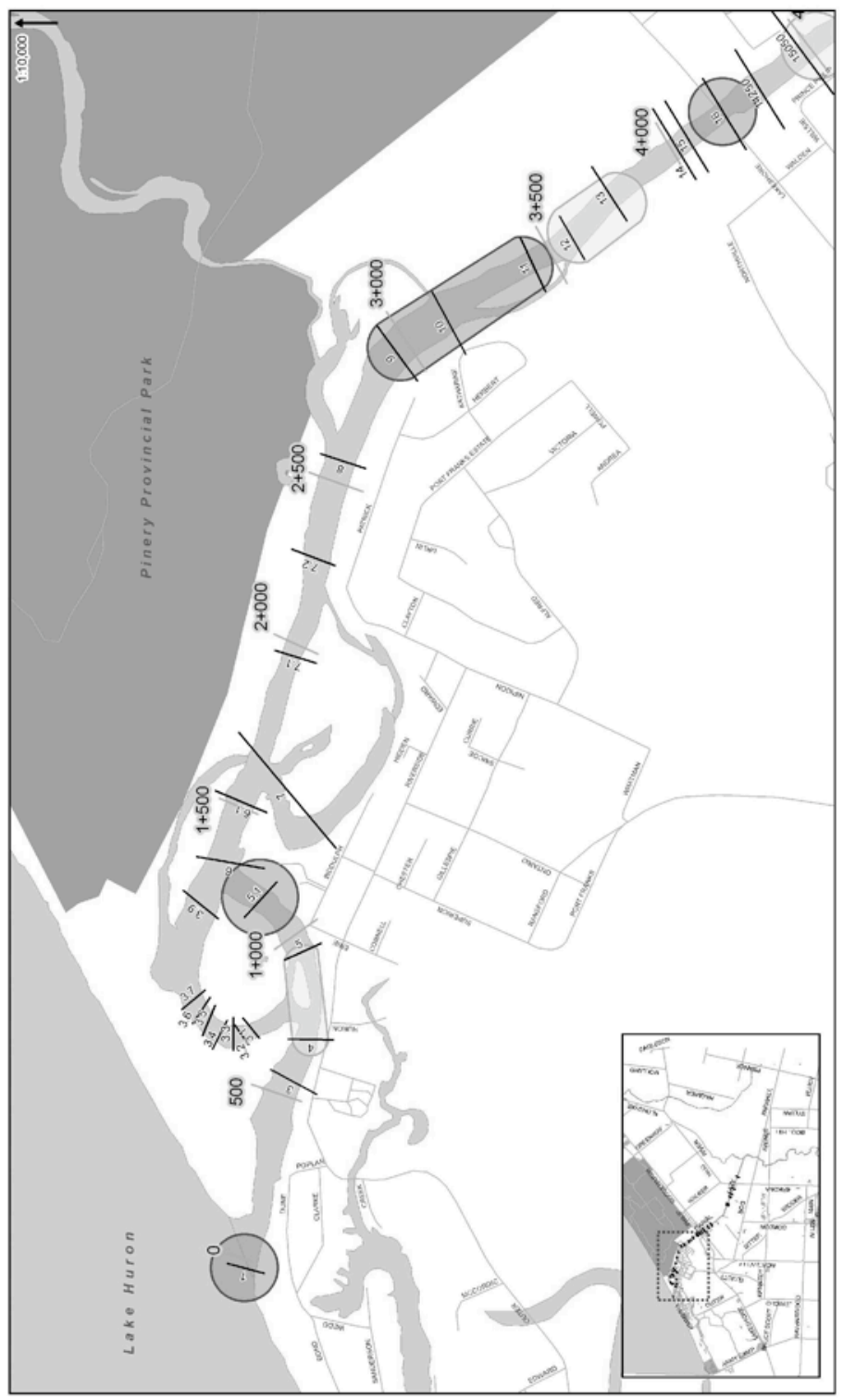

Figure 17.5 Priority ice jam potential locations (dark circle/ellipse = high risk, light circle/ellipse $=$ medium risk) . 


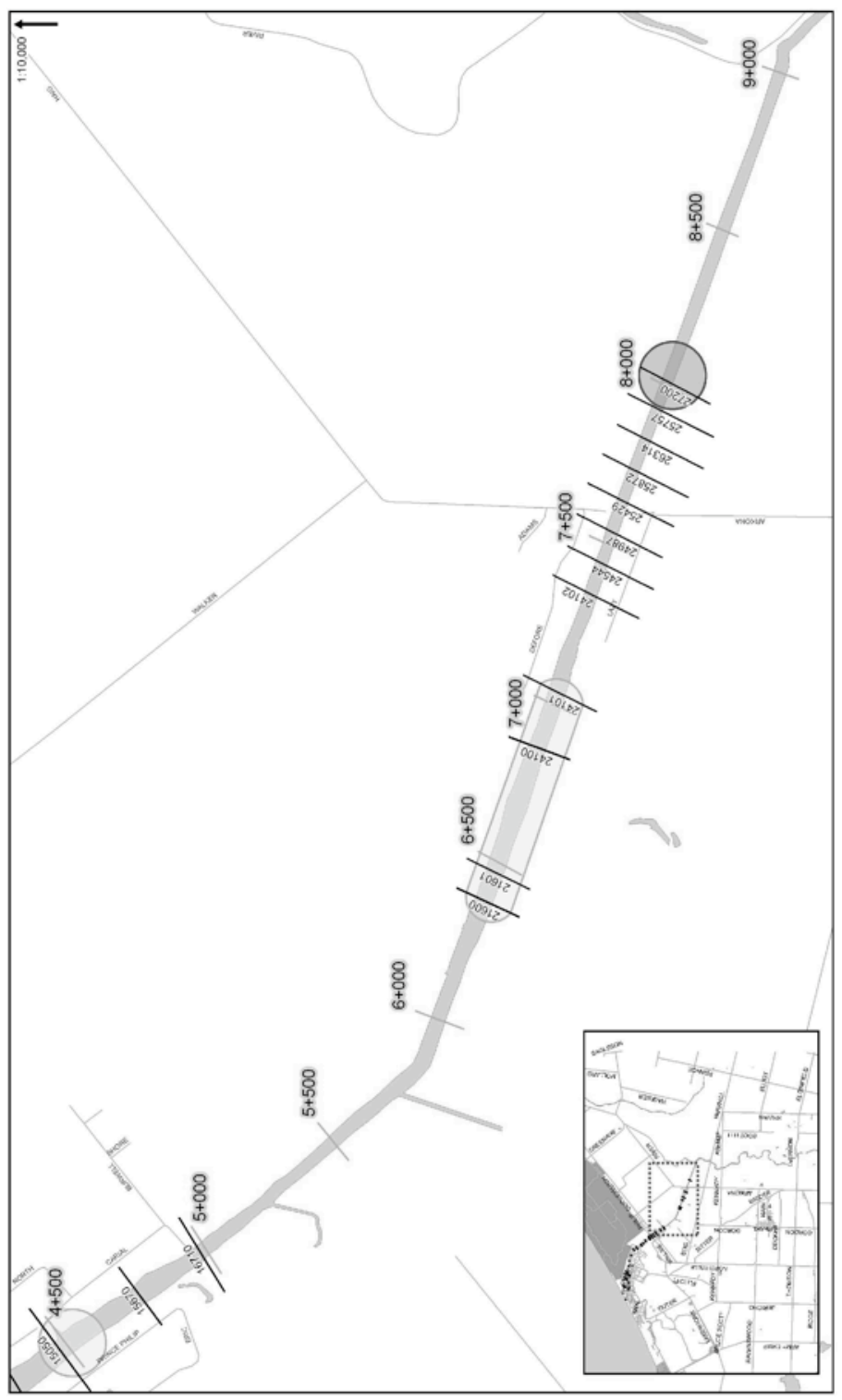

Figure 17.6 Priority ice jam potential locations (dark circle/ellipse = high risk, light circle/ellipse $=$ medium risk). 
River sections 9 through 11 are located at a sand/gravel bar downstream of a highway crossing, and river section 16 is located immediately upstream. These two areas have had historical ice jam occurrences, and confirmation of the potential for ice jams to occur at these areas by the hydraulic model further justifies pursuit of mitigative action at these critical areas.

\subsection{Ice Management Alternatives}

Several options have been considered to mitigate the flooding effects due to ice jams that have been experienced in this area. The following remedial options are described in detail below:

1. Dredging;

2. Ice cuts;

3. Flood-proofing berms;

4. Ice jam removal;

5. Ice booms;

6. Storage to reduce flows (construction of earthen dam);

7. Flood relief (construction of river bypass);

8. Re-open original river mouth;

9. Ice blasting;

10. Flood warning system;

11. Maintenance and administrative measures; and

12. No action.

Available alternatives include two main types:

- Alternatives that prevent ice jams by promoting a stable ice cover or reducing the factors which cause ice jams; and

- Alternatives that deal with, or reduce the effect of the ice jams which may occur.

Alternatives that prevent ice jams are generally more effective than those that mitigate the effects of jams. Options 1 and 6 represent preventative methods to reduce or alter flow such that ice jams are less likely to occur. The remaining options represent remedial measures to alleviate the ice jamming that occurs throughout the reach.

\subsubsection{Dredging}

It is anticipated that lowering the streambed invert and eliminating the obstructions would lower the flow velocities and thus lower the Froude number to a 
level where ice jam potential is less likely. In this and previous studies, three alternative dredging scenarios were evaluated:

1. A full channel cleanout along the entire length of the Lower Ausable River was represented using the channel improvement card in the hydraulic model. A trapezoidal section having a constant width of $30 \mathrm{~m}(100 \mathrm{ft})$ was used between the river banks with a side slope of 2:1 until it reaches the original ground;

2. Local channel improvements were represented in this scenario, with dredging to the same geometry as alternative 1, but only at selected high risk locations; and

3. Local improvements at high risk locations were also represented in this scenario, however a channel improvement card (with $30 \mathrm{~m}$ width) was not used for this model. Instead, the geometry of the dredge varied by width in order to reduce the Froude number below an acceptable tolerance (Froude number $<0.25$ ) at each section. The estimated amount of dredging required in this scenario is approximately $85000 \mathrm{~m}^{3}$ (70 acre- $\mathrm{ft}$ ).

\subsubsection{Ice Cuts}

This approach includes the cutting of slots along the river to provide for flow of

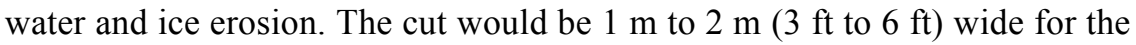
length of the study area. The ice would have to be removed to allow for water flow. Ideally, if the lake is open the cuts would start at the lower end and ice could be carried to the lake. This approach provides for an open water area and the erosion of the exposed ice edge.

For this approach to be effective, the ice cut has to be made when conditions are warm enough to prevent freeze up (during warm days). Hence, the window of opportunity is usually small, generally one or two weeks during winter.

\subsubsection{Flood-proofing Berms}

Based on historical flooding reports and confirmed through hydraulic modeling, the area with the highest flood potential is primarily in the Lazy Acres, Defore Subdivision (Plan 41) and the Four Corners area in Port Franks. A berm was installed in the Lazy Acres and Defore Subdivisions between 1988 and 1990 to reduce the risk if ice jam flooding of structures in these locations. 
This option includes installing flood-proofing berms similar to those previously constructed in the remaining ice jam areas. This alternative may also require raising of roads and buildings in areas where the berm cannot provide sufficient protection to the regulatory flood level.

\subsubsection{Ice Jam Removal}

In the past, some ice removal has been carried out during ice jam events. This can be continued, however removal is difficult given the river width. Removal of ice at the lake could also be carried out, however the feasibility is likely very limited given the volume of ice and the danger involved in the process. Ice removal would be limited to favorable weather conditions.

\subsubsection{Ice Booms}

Ice booms have been used successfully in slow moving water conditions to hold back ice from areas with high ice jam potential. This approach is to construct concrete anchors and cables or chains with wooden blocks across the river to hold ice in place, thereby taking advantage of storage in the upper reaches of the river. Certain conditions and considerations are necessary, including:

- The river bedslope must be flat or the water slow moving to allow for ice storage;

- A number of booms are generally required to provide for ice storage;

- Scour can occur if ice or water pass around the berm in high flows; and

- There is potential for some of the ice to pass over or under the boom during high flows.

\subsubsection{Storage to Reduce Flows (Construction of Earthen Dam)}

The construction of an upstream dam would reduce flow and limit the potential for ice jam. A normally stable ice cover breaks up during rapid changes in water level, and therefore by reducing flow and velocity, water levels can be controlled with the construction of a dam. A slow rate of rise in levels results in less ice per unit length of river; thus floodwater does not need to compete for space, thereby reducing the flood potential. In this case it is necessary to reduce upstream flows below the critical flowrate. 
The earthen dam option was first explored in a 1949 ABCA report and later updated (Kilborn, 1973). The proposed dam was to be located within a natural valley east of the village of Arkona. The proposed dam covered an area of approximately 930 ha (2 300 acre) with a maximum water depth of $12 \mathrm{~m} \mathrm{(40} \mathrm{ft).}$ The feasibility of this option rests primarily on costs and environmental impacts, which are anticipated to be prohibitively infeasible.

\subsubsection{Flood Relief (Construction of River Bypass)}

Constructing a river bypass would allow a portion of the flow to discharge more effectively into Lake Huron during high flow events. A channel would be created with a similar width to the upstream river and an invert located at an elevation corresponding to the critical flow water level. It is expected that when flood levels reach the critical flow, the bypass channel would facilitate positive discharge and reduce the effect on upstream lands.

The new channel would be located at cross-section 3.7 and would extend $180 \mathrm{~m}(590 \mathrm{ft})$ between the river and Lake Huron, along the original river cut through Armstrong West. Erosion protection would be placed at the upstream and downstream ends as well as along the banks. Regular maintenance would be required to remove potential sediment deposits.

This option would provide flood relief if an ice jam occurred in the lower reach of the river (in the main branch south of Armstrong West). In this way flood flows could bypass the river mouth into Lake Huron, thereby reducing upstream flood levels. Benefits would be limited however, since no relief would be provided if ice jams occurred in the upper river reaches.

\subsubsection{Re-open Original River Mouth}

A new full depth channel would serve a similar function to the flood relief option. Jetties would be provided to maintain marine traffic and prevent littoral drift from entering the channel. This option must consider the protection of an entrance for marine traffic as well as the prevention of local ice jam conditions. It is not expected that ice jam potential would be reduced in the upstream reaches.

\subsubsection{Ice Blasting}

Ice blasting has been carried out in the past to break up ice jams in a number of 
areas. This practice has been largely discontinued since the 1970s due to safety concerns and limited success.

\subsubsection{Flood Warning System}

A warning system can be effective in reducing the potential for flood damages and risk to life. It can be used to provide warning so that people can move from the area and that utilities can be shut down to reduce damage costs. A warning system for ice related flooding is difficult to implement however, given the complexity in predicting jam potential accurately and determining the resulting flood levels.

\subsubsection{Maintenance and Administrative Measures}

A number of maintenance and administrative measures could be developed by the Municipality of Lambton Shores and ABCA with respect to ice management, including:

- Adopt a program to clear trees and other floating debris that could increase the potential for ice jams;

- Continue administration of dock locations to ensure that ice jam potential is not increased;

- Continue strict control of new development in floodplain areas (current ABCA regulations) to ensure that flood risk does not increase;

- Possibly add freeboard ( $0.3 \mathrm{~m}$ to $0.5 \mathrm{~m}$, or $1 \mathrm{ft}$ to $1.5 \mathrm{ft})$ to current regulatory flood elevations;

- Preserve areas that provide flow relief during ice jams (e.g. old oxbows) and consider need for long term maintenance of relief flow paths; and

- Protect location of original river cut location and consider possible removal of material for flow relief.

\subsubsection{No Action}

This approach involves taking no action to prevent or mitigate the impacts of flooding due to ice jams. Ice jam problems and the resulting damage to property would continue to occur. 


\subsection{Recommended Ice Management Plan}

\subsubsection{Implementation Strategy}

The Lower Ausable River features characteristics that are favorable to forming ice jams and lands along the river are particularly prone to ice jam related flooding. The key conditions that affect the high risk potential for ice jam and related flooding include:

- Significant production of ice floes from the upper reaches of the Ausable River (upstream of the Old Iron Bridge);

- Sedimentation and scour within the study area result in a significant variation is streambed elevation and areas of ice jam potential;

- The backwater effect of Lake Huron and flat channel slope results in the formation of a stable ice cover during winter months; and

- Low bank heights in some development areas result in significant flood potential.

Given the nature of these conditions, there is no single solution available to provide a significant reduction in the ice jam potential throughout the entire Lower Ausable River. Therefore the recommended ice management plan features a combination of measures including:

- Measures to reduce the potential for ice jam (dredging, ice booms, and maintenance operations); and

- Measures to mitigate the impacts of flooding caused by ice jams (flood-proofing berms and administrative procedures).

The recommended ice management plan follows the preferred approach developed in the previous ice management studies and has been updated to consider new survey data, cost estimates, and permitting considerations that were not addressed in previous studies. Activities in the recommended ice management plan are summarized as follows:

- Maintenance and administrative measures (jointly by ABCA and Lambton Shores);

- Dredging (alternative 3, local dredge at high risk locations); and

- Flood-proofing berms (in Plan 41 and the Four Corners area of Port Franks).

The remaining alternatives were not selected for inclusion in the ice management plan due to issues of cost (flood bypass, storage to reduce flows), 
safety (ice blasting, ice cuts, ice jam removal) or infeasibility (re-opening of original river mouth, ice booms).

The maintenance and administrative measures and the dredging option are recommended to proceed immediately. Further, a phased implementation plan was developed to dredge the high risk locations over a four-year period, with Year 1 dredging of river sections 9,10 and 11 , representing a dredge volume of approximately $27000 \mathrm{~m}^{3}$ (22 acre-ft). Figure 17.7 shows the location of the priority Year 1 dredging location, which includes a diamond-shaped sandbar in the middle of the river. Note the main navigable channel is in the south channel braid in the background.

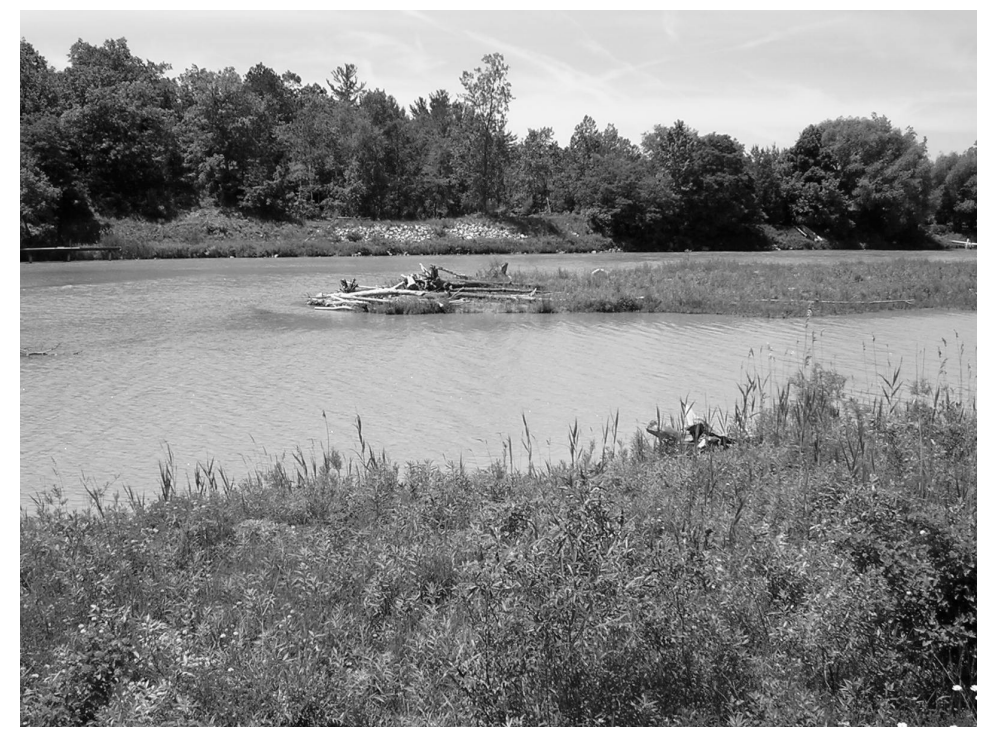

Figure 17.7 Priority dredge location (looking south near river section 11).

The implementation of the flood-proofing berms options could proceed if funding were to become available.

\subsubsection{Permitting Process}

The environmental permitting and approvals process for the routine maintenance dredging proposed in the Year 1 implementation strategy involves a 
number of federal and provincial agencies, including:

- $\quad$ Fisheries and Oceans Canada (DFO) primarily concerned with the potential for harmful alteration, disruption, or destruction of fish habitat;

- Transport Canada-Navigable Waters Protection (NavWaters) primarily concerned with public rights of navigation and safety to boaters; and

- Ontario Ministry of Natural Resources (MNR) primarily concerned with fisheries timing windows.

The Ontario Operational Statement for the federal Habitat Management Program deals with routine maintenance dredging associated with the removal of accumulated sediment from channel beds to maintain the design depths of existing public use facilities, which includes navigation channels. It is noted in this statement that the largest threat to fish and fish habitat is from the increased amount of suspended sediment introduced to the water column during the dredging process.

The dredging option proposed in the Year 1 implementation strategy is outside of the portion that would qualify as routine maintenance dredging and therefore both DFO and NavWaters review is required for this project. In addition, approval is also required under the ABCA regulation O.Reg. 147/06. The challenges encountered during the DFO permitting process are described in the following section.

\subsubsection{New Protocols for Freshwater Bivalve Species (Mussels)}

DFO is responsible for protecting fish and fish habitat across Canada. Under Section 35 of the Fisheries Act, no one may carry out a work or undertaking that will cause the harmful alteration, disruption or destruction (HADD) of fish habitat unless it has been authorized by DFO.

The local DFO representative indicated their primary concern is with species-at-risk (SAR) bivalve populations, particularly in the priority dredge location downstream of Highway 21. Identified SAR mussels include the kidneyshell, northern riffleshell, snuffbox, and wavy-rayed lampmussel.

It was noted that DFO guidelines require an initial mussel survey and assessment at-depth and would need to be conducted at (and immediately downstream of) all proposed dredge locations. The survey team must include a minimum of four people (including at least one SAR mussel expert) for a minimum assessment duration of $4 \mathrm{~h}$ in an area not larger than $1000 \mathrm{~m}^{2}$ $\left(10000 \mathrm{ft}^{2}\right)$. The survey is to be conducted manually, normally during the 
months of June through September as it cannot be performed during water temperatures below $16^{\circ} \mathrm{C}\left(61^{\circ} \mathrm{F}\right)$ or during critical fish spawning periods.

If any SAR mussels are found and the proposed project might negatively impact habitat, a relocation-protection plan would need to be submitted for DFO approval. A separate DFO permit to relocate mussels would be required if the plan were approved.

ABCA staff conducted a preliminary site investigation in November 2007 for the purpose of identifying critical mussel habitat areas within the Lower Ausable River. The objectives of this investigation were to:

- Characterize the quality and quantity of potential mussel habitat;

- Identify the areas where mussels were observed; and

- Identify the mussel species where present.

In this investigation, four mussel habitat areas were identified and the priority dredge location near river section 11 was identified as the most critical.

On June 28 and 29, 2008, Water Systems Analysts Inc. performed a detailed SAR mussel survey in the priority dredge location. The search was conducted under the supervision of Dr. Gerald Mackie, an internationally recognized mussel expert.

The search was conducted by distributing $3001.0 \mathrm{~m}^{2}$ quadrants throughout the prescribed search area, yielding a search area with a $95 \%$ probability of finding SAR mussels. These quadrants were located along 80 transects throughout the search area as shown on Figure 17.8.

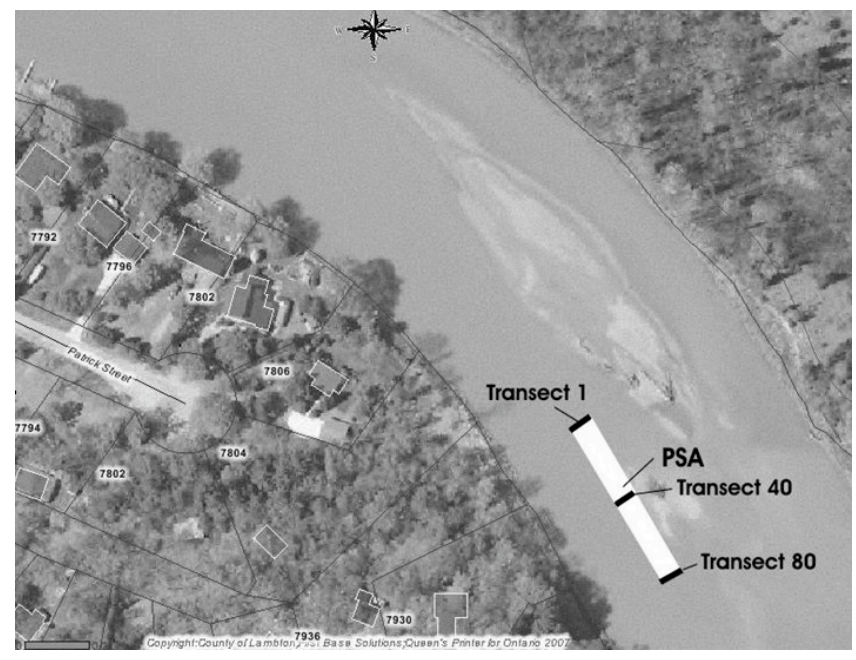

Figure 17.8 Mussel survey prescribed search area. 
Following the DFO protocol, the following precautions were taken during the survey to minimize harm to mussels:

- Limiting exposure of mussels to atmosphere to $<30 \mathrm{~s}$, the time required to identify the species;

- Returning mussels to their original positions and orientations;

- Removing mussels by hand and not with tools; and

- Taking care not to step on any mussels during the search.

Table 17.3 shows the mussel species that were found during the survey. As a result of this investigation, it was concluded that no species-at-risk mussels were found, either dead or alive, in the priority dredge location.

Table 17.3 Summary of mussel species surveyed.

\begin{tabular}{lc}
\hline \multicolumn{1}{c}{ Mussel species } & Number found \\
\hline LIVING & \\
Three-ridge & 37 \\
Wabash Pigtoe & 5 \\
White Heelsplitter & 1 \\
DEAD & \\
Deertoe & $10-20$ \\
Fatmucket & $3-5$ \\
Fragile Papershell & $5-10$ \\
Mucket & $5-10$ \\
Pimpleback & 1 \\
Pink Heelsplitter & 1 \\
Purple Wartyback & 1 \\
\hline
\end{tabular}

Despite no evidence of SAR mussels, DFO still considers that critical residence habitat has been established at this location and that dredging would qualify as a HADD. As a result, the federal environmental assessment process would be required for any proposed dredging operations and DFO would assess the categorization of risk.

The disposal of dredged material also presents challenges with apparent conflicting interests from a navigational perspective (which would encourage removing the dredgeate from the river) and an environmental perspective (which would encourage keeping the sediment in the river system). For this project, broadcasting the dredgeate at the mouth of the river appears to be a more acceptable and lower cost option than hauling the material off-site.

\subsection{Conclusions}

This chapter highlighted the key project features of an ice management plan for the Lower Ausable River near Port Franks, Ontario. This is a dynamic river 
system that has experienced significant flooding, erosion and ice hazards in the past. These problems have been influenced by prior human development activity that modified the original dynamics of the river, as well as by levels in Lake Huron which are cyclical in nature. Several alternatives to mitigate the risk of flooding due to ice jams were evaluated, and an ice management plan was developed accordingly.

The key feature of the recommended ice management plan involves dredging of the river bed at priority locations to improve hydraulic characteristics. With new federal protocols for mussel sampling procedures and potential relocation plans, this option presented implementation challenges. These protocols are beginning to impact other water resources projects throughout Ontario and may have implications to any proposed in-stream works in Canada that feature SAR mussel populations or their residence habitat.

\section{References}

Gregory, M., R. Tufgar, A. Scott, K. Hall and S. Seabrook. 2008. "Minimizing Erosion Hazards in a Dynamic River System." Journal of Water Management Modeling R228-06. doi: 10.14796/JWMM.R228-06.

Haestad Methods, 2003. Floodplain Modeling Using HEC-RAS, First Edition. Kilborn

Engineering Ltd., October 1973. Report on Floodline Mapping, Ausable River and Mud Creek.

Michel, Bernard, 1978. Ice Mechanics. Les Presses de l’Universite Laval, Quebec City, Quebec.

Ontario Department of Planning and Development, 1949. Ausable Valley Conservation Report.

Pariset E, R. Hausser and A. Gagnon, 1966. Formation of ice covers and ice jams in rivers. Journal of the Hydraulics Division, American Society of Civil Engineers.

TSH (Totten Sims Hubicki Associates), January 2001. Port Franks Ice Management Study 2000. Final Report.

TSH (Totten Sims Hubicki Associates), June 2005. Port Franks - Armstrong West Erosion Control Works. Class Environmental Assessment, Project Plan.

TSH (Totten Sims Hubicki Associates) and Samuel Lazier, October 1999. Port Franks Ice Management Study. Final Report.

Triton Engineering, November 1991. Port Franks Harbour Management Study. 